\title{
Ex Vivo Tracking of Endogenous CO with a Ruthenium(II) Complex
}

\author{
Cristina de la Torre, ${ }^{\dagger, \ddagger, \$,+}$ Anita Toscani, ${ }^{\|,+}$Cristina Marín-Hernández, ${ }^{\dagger,+, \S}$ Jonathan A. Robson," \\ María Carmen Terencio, ${ }^{\S, \perp}$ Andrew J. P. White," María José Alcaraz, ${ }^{\S, \perp}$ James D. E. T. Wilton-Ely, ${ }^{*, l}$ \\ Ramón Martínez-Máñez, ${ }^{*}, t, t, \S \odot$ and Félix Sancenón ${ }^{\dagger, t, 8}$
}

${ }^{\dagger}$ Instituto Interuniversitario de Investigación de Reconocimiento Molecular y Desarrollo Tecnológico (IDM), Universitat Politècnica de València, Universitat de València, 46022 Valencia, Spain

${ }^{\ddagger}$ Departamento de Química, Universitat Politècnica de València, Camino de Vera $\mathrm{s} / \mathrm{n}, 46022$ Valencia, Spain

${ }^{\S}$ CIBER de Bioingeniería, Biomateriales y Nanomedicina (CIBER-BBN), Spain

"Department of Chemistry, Imperial College London, South Kensington Campus, London SW7 2AZ, United Kingdom

${ }^{\perp}$ Department of Pharmacology, Universitat de València, 46010 Valencia, Spain

\section{Supporting Information}

ABSTRACT: A two-photon fluorescent probe based on a ruthenium(II) vinyl complex is capable of selectively detecting carbon monoxide in cells and ex vivo using mice with a subcutaneous air pouch as a model for inflammation. This probe combines highly selective and sensitive ex vivo detection of endogenous $\mathrm{CO}$ in a realistic model with facile, inexpensive synthesis, and displays many advantages over the widely used palladium-based systems.

$\mathrm{T}$ he toxic effect of carbon monoxide in humans is due to the high affinity of $\mathrm{CO}$ for iron, reducing the oxygen transport capacity of hemoglobin, and the fact that the gas is broadly inhibitory for heme proteins and nonheme iron enzymes, including hydrogenase ${ }^{1}$ and nitrogenase. ${ }^{2}$ Paradoxically, more than half a century ago it was found that $\mathrm{CO}$ is routinely formed endogenously in humans in small quantities, and that under certain pathophysiological conditions, $\mathrm{CO}$ production increases. ${ }^{3}$

In the body, $\mathrm{CO}$ serves many functions, including antiinflammatory, antiproliferative, antiapoptotic and anticoagulative roles. It is also an intrinsic metal ligand in enzymes and acts as a gaseous signaling molecule in mammals. ${ }^{4}$ Hemoglobin is required as a substrate for the production of $\mathrm{CO}$ in vivo and heme oxygenases (HO-1 and $\mathrm{HO}-2$ ) are implicated in the generation of this gas in mammals. There is also evidence that an increased generation of $\mathrm{HO}$-derived $\mathrm{CO}$ plays a critical role in the resolution of inflammatory processes and alleviation of cardiovascular disorders. ${ }^{5}$

CO-releasing molecules (CORMs) are capable of liberating controlled amounts of $\mathrm{CO}$ in biological systems and this has led to their investigation for the prevention of vascular dysfunction, inflammation, tissue ischemia and organ rejection. ${ }^{6}$

One of the major obstacles limiting progress in understanding the biological role of $\mathrm{CO}$ and its therapeutic application is the lack of real-time methods to selectively track $\mathrm{CO}$ in biological systems. Recently, fluorescence sensing and imaging with emissive probes has emerged as one of the most powerful techniques to detect biologically important molecules. ${ }^{7}$ Until very recently, the most significant breakthroughs came from the groups of $\mathrm{He}^{8}$ and Chang, ${ }^{9}$ which reported two different types of fluorescent probes for the imaging of $\mathrm{CO}$ in living cells. Following those pioneering contributions, many probes (almost all based on palladium) have been developed and applied for cell imaging of CO.$^{10}$ However, these probes are either complicated, difficult to synthesize, require excitation by photodamaging UV light, have delayed fluorescence response times (commonly between 40 and $60 \mathrm{~min}$ in the palladium-based systems), use cytotoxic nonligated heavy metal salts (as carbonylation catalysts or Tsuji-Trost reaction mediators) or the addition of high concentrations of organic cosolvents. ${ }^{10}$ For these reasons, the development of a simple fluorogenic probe with improved features capable of detecting CO in living systems is therefore a particularly timely area of research.

Two-photon fluorescence microscopy offers many advantages over conventional confocal microscopy. It allows the study of biological samples in three dimensions with submicrometer resolution, while the near-IR light used reduces specimen photodamage and provides greater penetration, allowing higher contrast imaging. This has led to substantial interest in the design of new two-photon fluorophores for biological sensing. ${ }^{11}$

In view of the aspects mentioned above, we report herein a novel molecular probe for the two-photon fluorogenic detection of $\mathrm{CO}$ in biological environments using the IDA paradigm pioneered by Anslyn. ${ }^{12}$ The probe (complex 6 in Scheme 1) takes inspiration from previously described ruthenium(II) complexes with fluorogenic vinyl substituents, which display exceptional results for the detection of $\mathrm{CO}$ in air. ${ }^{13}$ However, a crucial difference in compound $\mathbf{6}$ is the use of a new fluorophore, 5-(3-thienyl)-2,1,3-benzothiadiazole (TBTD), as a signaling unit, which is coordinated directly to the metal center. A major drawback of these previously reported ruthenium(II) vinyl complexes is their very low water solubility which prevents their direct application for $\mathrm{CO}$ sensing in aqueous systems. The use of water-soluble phosphines was found to lead to undesired effects on the sensing behavior so an alternative strategy was employed to introduce hydrophilic groups to the vinyl substituent. Probe $\mathbf{6}$ was successfully

Received: October 31, 2017

Published: November 28, 2017 
Scheme 1. (a) Synthesis of HC $\equiv C L$; (b) Preparation of 6 and Reaction of 6 with CO; (c) Crystal Structure of TBTD (Supporting Information)
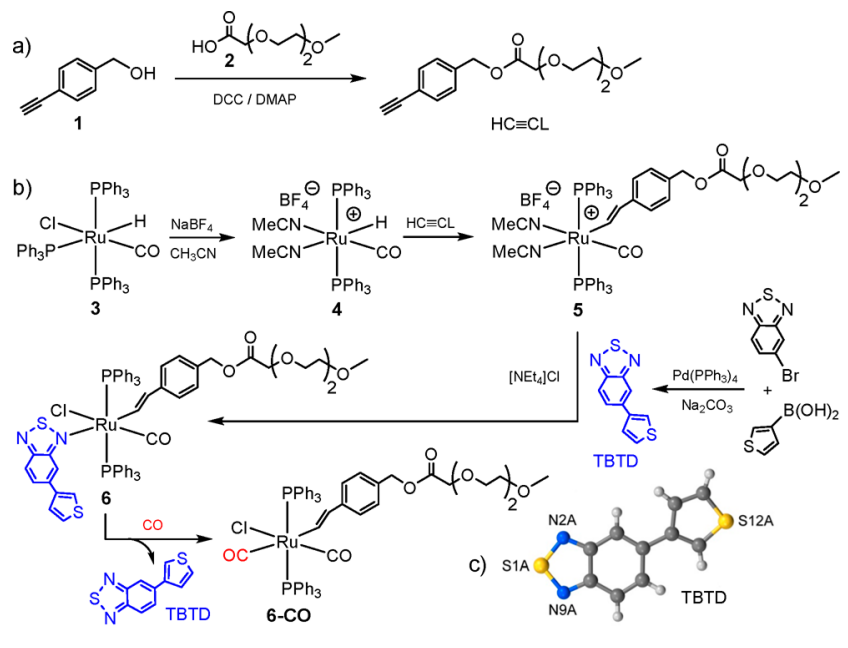

synthesized using a terminal alkyne with an oligoethylene glycol moiety ( $\mathrm{HC} \equiv \mathrm{CL}$ in Scheme 1). The design of $\mathbf{6}$ thus incorporates many characteristics needed for the sensing of carbon monoxide in cells. Its solubility in water, the immediate fluorogenic response, the outstanding emission enhancement and the exceptional sensitivity and selectivity make this complex a unique candidate for this application (vide infra).

The new two-photon fluorophore, TBTD, was prepared using a Suzuki coupling and was spectroscopically and structurally characterized (Supporting Information). The synthesis of probe 6 is shown in Scheme $1 b$, commencing from commercially available 3. Perhaps due to the oligoethylene glycol chain, compound 6 failed to yield crystals suitable for a structural determination. In order to unequivocally determine the bonding mode and orientation of the coordinated TBTD ligand, the 9phenanthrenyl analogue $[\mathrm{Ru}(\mathrm{CH}=\mathrm{CHPhen}-9) \mathrm{Cl}(\mathrm{CO})$ $\left.(\mathrm{TBTD})\left(\mathrm{PPh}_{3}\right)_{2}\right](7)$ was prepared (Supporting Information). $\mathrm{X}$-ray diffraction of single crystals of 7 and its $\mathrm{CO}$ adduct (7• CO) ${ }^{13 a}$ allowed structural information to be obtained (Figure 1).

The fluorogenic behavior of probe 6 in aqueous environments was first investigated in the absence and in the presence of $\mathrm{CO}$. Analysis of a PBS ( $\mathrm{pH} 7.4$ )-acetone 99.9:0.1 v/v solution of probe $6\left(1.0 \times 10^{-5} \mathrm{~mol} \mathrm{~L}{ }^{-1}\right)$ revealed a very weak emission band centered at ca. $500 \mathrm{~nm}$ (upon excitation at $355 \mathrm{~nm}$ ). The weak nature of this emission was ascribed to quenching of the TBTD fluorescence by the $\mathrm{Ru}$ (II) center (heavy atom effect). Passing increasing quantities of $\mathrm{CO}$ gas into the aqueous solution of probe 6 induced a progressive enhancement of the emission at $500 \mathrm{~nm}$ (Figure 2). The observed emission enhancement was attributed to the dissociation of TBTD from the complex upon $\mathrm{CO}$ binding and this displacement was confirmed experimentally (Figure S2-20). The replacement of the labile TBTD ligand by $\mathrm{CO}$ was found to disrupt the quenching effect of the $\mathrm{Ru}(\mathrm{II})$ center and accounted for the emission enhancement observed (see Scheme $1 \mathrm{~b}$ ). The product formed, $\left[\mathrm{Ru}(\mathrm{CH}=\mathrm{CHL}) \mathrm{Cl}(\mathrm{CO})_{2}\left(\mathrm{PPh}_{3}\right)_{2}\right](6 \cdot \mathrm{CO})$, was also fully characterized (Supporting Information).

The stability of complex 6 in aqueous solution was assessed by recording fluorescence spectra every $5 \mathrm{~min}$ in the presence and absence of $\mathrm{CO}$ over a $1 \mathrm{~h}$ period. As no emission enhancement was observed in the absence of $\mathrm{CO}$, it can be

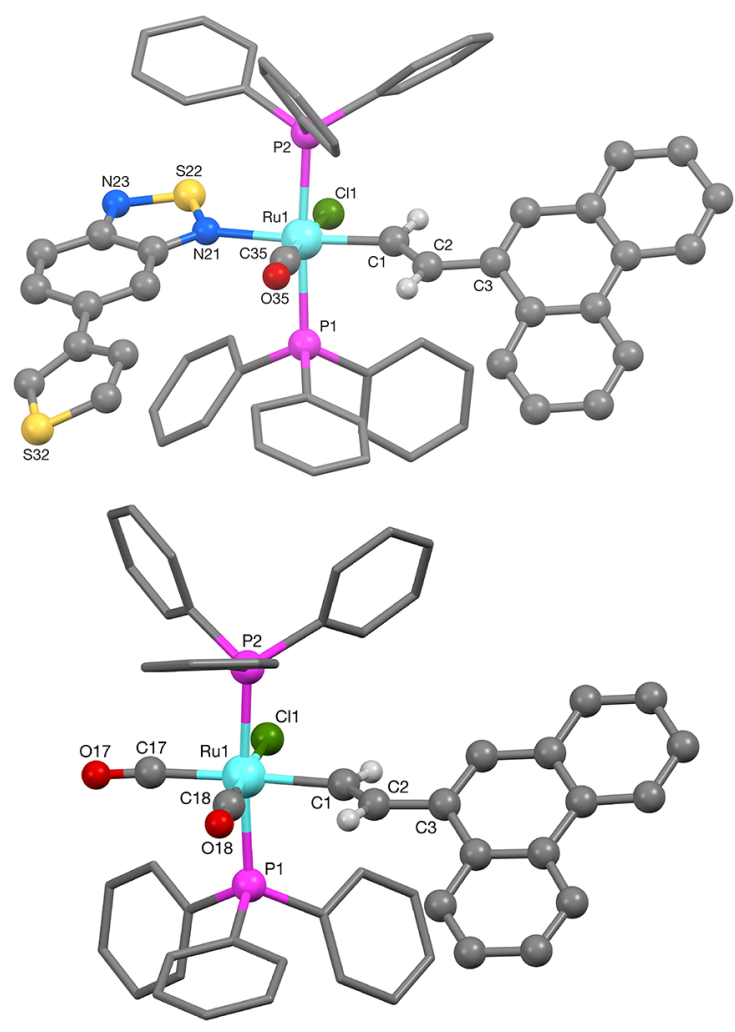

Figure 1. Crystal structures of 7 (above) and $7 \cdot \mathrm{CO}$ (below).

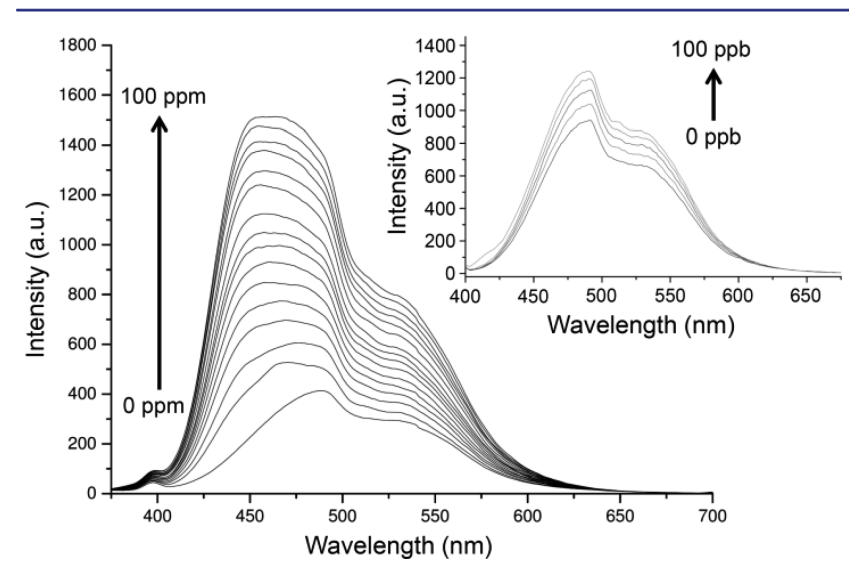

Figure 2. Turn-on fluorescence response (excitation at $355 \mathrm{~nm}$ ) of a $1.0 \times 10^{-5} \mathrm{~mol} \mathrm{~L}^{-1}$ of PBS ( $\mathrm{pH} 7.4$ )-acetone 99.9:0.1 v/v solution of probe 6 upon addition of increasing quantities of $\mathrm{CO}(0-100 \mathrm{ppm}$ and $0-100 \mathrm{ppb})$.

concluded that the fluorescence response results from the presence of this gas in solution and not due to spontaneous release of the TBTD ligand (e.g., through displacement by water). Although the cellular matrix is difficult to reproduce, 100 $\mu \mathrm{M}$ concentrations of reactive nitrogen and oxygen species, such as tryptophan, cysteine, BSA, imidazole, $\mathrm{NO}_{x}$, hydroxide, peroxide, were also added to aqueous solutions of probe 6 , while the emission intensity was monitored. No significant increase in the TBTD emission was observed on addition of these compounds, confirming the selectivity of the probe toward CO (Figure S4-2). Further tests confirmed the solution and photostability of probe 6 (Figures S4-4, S4-5 in Supporting Information). 
These experiments successfully demonstrated the potential of probe 6 for sensing $\mathrm{CO}$ in cells as the probe is (i) sufficiently soluble in water, (ii) selective for $\mathrm{CO}$, producing a remarkable fluorescence enhancement, (iii) emissive at higher wavelengths than the range typical of protein emissions $(250-400 \mathrm{~nm})$ and (iv) two-photon active (vide infra). These design properties are vitally important for single-molecule imaging in cells.

Following the encouraging results described above, the imaging of $\mathrm{CO}$ in living cells was investigated using probe 6 . The mouse macrophage RAW 264.7 cell line was selected as it can induce $\mathrm{HO}-1$ and generate $\mathrm{CO}$ under different physiological conditions. ${ }^{14}$ Viability assays (MTT) using RAW 264.7 cells demonstrated the nontoxicity of probe 6 , also in the presence of CORM-3 and hemin (Figure S5-1). Following this favorable toxicity assessment, the ability of probe 6 to visualize changes in CO levels in cells was tested. RAW 264.7 cells were incubated with probe $6(10 \mu \mathrm{M})$ for $30 \mathrm{~min}$, leading to no discernible emission (Figure 3A). However, when the cells were
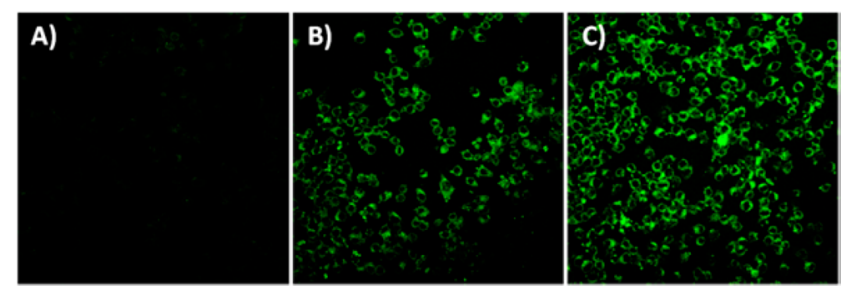

Figure 3. Two-photon excitation microscopy images of RAW 264.7 cells treated for 30 min with (A) $0 \mu \mathrm{M}$, (B) $10 \mu \mathrm{M}$, and (C) $50 \mu \mathrm{M}$ of CORM-3 followed by $10 \mu \mathrm{M}$ of probe 6 in PBS (pH 7.4)-acetone 99.9:0.1 v/v. Images acquired upon excitation at $715 \mathrm{~nm}$.

preincubated with the CO source, CORM-3, and then treated with probe $6(10 \mu \mathrm{M})$, a dose-dependent intracellular twophoton fluorescence response was clearly observed (Figure 3B,C).

Carbon monoxide is naturally generated by the action of $\mathrm{HO}$ on heme produced by the rupture of hemoglobin. Also, heme administration is known to increase $\mathrm{HO}-1$ expression and activity leading to subsequent $\mathrm{CO}$ generation. ${ }^{15}$ Accordingly, RAW 264.7 cells were treated with hemin chloride in order to enhance intracellular CO levels, and so to further examine the ability of probe 6 to detect CO. Again, MTT viability assays were carried out to assess the toxicity of the hemin/probe 6 treatment in RAW 264.7 cells. Cells were treated with hemin $(100 \mu \mathrm{M})$ for $0.5,3$, and $6 \mathrm{~h}$ and then probe $6(10 \mu \mathrm{M})$ was added 30 min before imaging. Two controls were used: (i) cells without any treatment and (ii) cells treated only with probe 6 $(10 \mu \mathrm{M})$ for $30 \mathrm{~min}$. The viability experiments showed no toxicity for 6 in the presence of hemin (Figure S5-1).

RAW 264.7 cells were incubated with hemin $(100 \mu \mathrm{M})$ for 3 $\mathrm{h}$, then with probe $6(10 \mu \mathrm{M})$ for $5,10,20$, and $30 \mathrm{~min}$ prior to imaging. The two-photon excitation microscopy images obtained are shown in Figure S5-2. The RAW 264.7 cells treated with hemin and probe 6 showed a marked green emission that was again ascribed to the TBTD fluorophore released from probe 6 upon reaction with the $\mathrm{CO}$ generated. Moreover, a dose dependent response was observed when cells were treated with different hemin concentrations during the same time period (Figure 4). This showed a 10 -fold enhancement when $100 \mu \mathrm{M}$ hemin was used.

The response time for $\mathrm{CO}$ detection in the above experiments was rapid with maximum emission after only $10 \mathrm{~min}$ of probe
A)

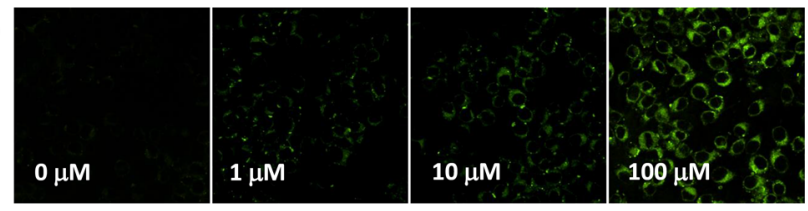

B)

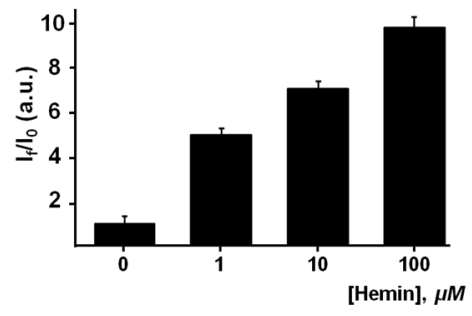

Figure 4. (A) Two-photon excitation microscopy images of RAW 264.7 cells treated with $0,1,10$, or $100 \mu \mathrm{M}$ of hemin for $3 \mathrm{~h}$ before incubation with probe $6(10 \mu \mathrm{M})$ for $10 \mathrm{~min}$. (B) Ratio of mean fluorescence intensity of cells plus control cells (no hemin) using ImageJ software. Data are expressed as mean \pm SEM of at least three independent experiments. Excitation at $715 \mathrm{~nm}$.

incubation (Figure S5-2). This compares favorably with the 60 min response time of the ground-breaking molecular probe reported by Chang. 9 The first two-photon system for CO detection in cells was the elegant cyclopalladated carbazolecoumarin scaffold reported by Lin et al. ${ }^{10 a}$ However, its drawbacks included the 7-step synthetic route from commercial reagents, the high CORM-2 concentration used $(200 \mu \mathrm{M})$ and the long response time $(40 \mathrm{~min})$. Even improved systems ${ }^{10 j}$ require $60 \mathrm{~min}$ for the best results and the nature and impact of the undefined $\mathrm{Pd}$ species released is unknown. Following confirmation that probe $\mathbf{6}$ successfully detects small changes in intracellular $\mathrm{CO}$, the potential and versatility of probe 6 for $e x$ vivo $\mathrm{CO}$ detection was explored using a subcutaneous air pouch inflammation mouse model.

The cellular stress protein HO-1 serves a vital metabolic function for limiting the rate of degradation of heme to generate carbon monoxide, iron and biliverdin- $\mathrm{IX}_{\alpha}$ (which converts to bilirubin- $\left.\mathrm{IX}_{\alpha}\right)^{5,6}$ Lipopolysaccharides (LPS) from many bacterial species initiate acute inflammatory responses in mammals that are typical of the host reaction to tissue injury or infection. In this scenario, LPS administration into a mouse air pouch induces an inflammatory reaction characterized by plasmatic exudation and migration of leukocytes to the cavity. ${ }^{16}$ It was anticipated that the LPS would induce HO-1 protein expression in leukocytes migrating to the air pouch exudates, causing them to exhibit higher levels of $\mathrm{CO}$ than would be expected in the absence of LPS. Air pouches were produced in female Swiss mice by subcutaneous injections of $10 \mathrm{~mL}$ sterile air into the back. After 3 days, $5 \mathrm{~mL}$ of sterile air were injected into the same cavity. Six days after the formation of air pouches, inflammation was induced by injection of $1 \mathrm{~mL}$ of LPS $(1 \mu \mathrm{g} / \mathrm{mL})$ in saline. A control group was only injected with $1 \mathrm{~mL}$ of saline. After $18 \mathrm{~h}, 3$ $\mathrm{mL}$ of probe $6(50 \mu \mathrm{M})$ was injected into the air pouch. After 30 min, mice were culled and the exudates in the pouch were collected and visualized using two-photon microscopy. As shown in Figure 5, cells from mice treated with LPS and probe 6 showed a remarkable increase in fluorescence (Figure 5D) compared to cells from mice treated with only saline and probe 6 (Figure 5C). As expected, a very low level of fluorescence was observed in cells from mice treated with LPS without probe 6 (Figure 5B) or only treated with saline (Figure 5A). These 

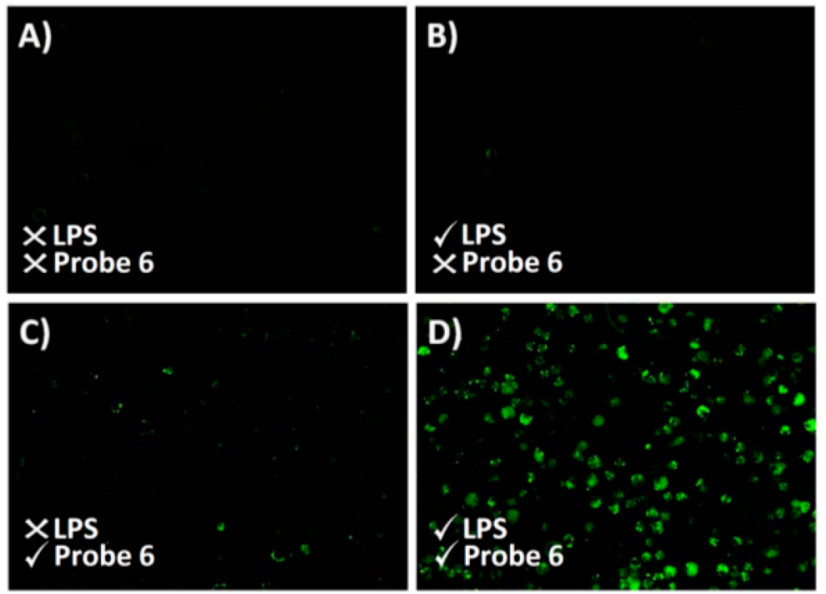

Figure 5. Two-photon excitation microscopy images of cells from mice exudates after $18 \mathrm{~h}$ of saline or LPS treatment and $30 \mathrm{~min}$ with or without probe 6 in the air pouch. (A) Mice treated with saline, (B) mice treated with LPS, (C) mice treated with saline and $50 \mu \mathrm{M}$ of probe 6 , (D) mice treated with LPS and $50 \mu \mathrm{M}$ of probe 6. Images were acquired upon excitation at $715 \mathrm{~nm}$ using a multiphoton microscope. See Figure S5-3 for larger images.

results clearly indicate that probe 6 is able to fluorogenically detect $\mathrm{CO}$ ex vivo in a model of inflammation.

In summary, we have described the design of a $\mathrm{Ru}(\mathrm{II})$ vinyl complex capable of selectively detecting $\mathrm{CO}$ through a remarkable OFF-ON emission enhancement in $\mathrm{PBS}(\mathrm{pH}$ 7.4)-acetone 99.9:0.1 v/v. Probe 6 is selective for $\mathrm{CO}$ even in the presence of RNS and ROS, which all induced no response. Probe $\mathbf{6}$ proved to be nontoxic to cells and can be used in low doses for the in vitro two-photon fluorescence imaging of $\mathrm{CO}$ in RAW 264.7 cells in the presence of CORM-3 or hemin. Even more significantly, the probe was successfully used for the ex vivo two-photon fluorescence detection of $\mathrm{CO}$ in cells collected from the exudates of an air pouch inflammation mouse model. The combination of selectivity, sensitivity and inexpensive, straightforward synthesis make the system described here a very attractive and efficient probe for the facile fluorogenic detection of this gas in realistic biological environments.

\section{ASSOCIATED CONTENT}

\section{S Supporting Information}

The Supporting Information is available free of charge on the ACS Publications website at DOI: 10.1021 /jacs.7b11158.

Text and figures giving information on general considerations, instrumentation, synthesis of TBTD, HC $\equiv \mathrm{CL}$, 6, 6. $\mathrm{CO}$ and 7 , crystallographic data and structures of 7 and $7 \cdot \mathrm{CO}$, selectivity studies, solution and UV stability studies for probe $\mathbf{6}$ and stability studies of $\mathbf{6}$ in the presence of interferents, cytotoxicity and microscopy studies including cellular internalization kinetics, animal preparation (PDF)

Data for TBTD, 7 and $\mathbf{7 \cdot C O}(\mathrm{CIF})$

\section{AUTHOR INFORMATION}

\section{Corresponding Authors}

*j.wilton-ely@imperial.ac.uk

*rmaez@qim.upv.es

\section{ORCID}

James D. E. T. Wilton-Ely: 0000-0002-5192-3038
Ramón Martínez-Máñez: 0000-0001-5873-9674

\section{Author Contributions}

${ }^{+}$These authors contributed equally

Notes

The authors declare no competing financial interest.

\section{ACKNOWLEDGMENTS}

The authors thank the Spanish government (Project MAT201564139-C4-1), the Generalitat Valencia (Project PROMETEOII/2014/047), CIBER-BBN, IC Global Engagements fund, Santander Mobility Award. C.T. is grateful to the Spanish Ministry of Science and Innovation, A.T. thanks the Leverhulme Trust (RPG-2012-634) and J.A.R. thanks the EPSRC, for PhD studentships. We thank the UV Microscopy service and E. Navarro Raga for multiphoton microscopy.

\section{REFERENCES}

(1) Rees, D. C. Annu. Rev. Biochem. 2002, 71, 221-246.

(2) Lee, H. I.; Cameron, L. M.; Hales, B. J.; Hoffman, B. M. J. Am. Chem. Soc. 1997, 119, 10121-10126.

(3) Sjoestrand, T. Nature 1949, 164, 580-581.

(4) Szabo, C. Nat. Rev. Drug Discovery 2016, 15, 185-203.

(5) Motterlini, R.; Otterbein, L. E. Nat. Rev. Drug Discovery 2010, 9, $728-743$.

(6) Kautz, A. C.; Kunz, P. C.; Janiak, J. Dalton Trans. 2016, 45, 18045-18063.

(7) Marín-Hernández, C.; Toscani, A.; Sancenón, F.; Wilton-Ely, J. D. E. T.; Martínez-Mañez, R. Chem. Commun. 2016, 52, 5902-5911.

(8) Wang, J.; Karpus, J.; Zhao, B. S.; Luo, Z.; Chen, P. R.; He, C. Angew. Chem., Int. Ed. 2012, 51, 9652-9656.

(9) Michel, B. W.; Lippert, A. R.; Chang, C. J. J. Am. Chem. Soc. 2012, 134, 15668-15671.

(10) (a) Zheng, K.; Lin, W.; Tan, L.; Chen, H.; Cui, H. Chem. Sci. 2014, 5, 3439-3448. (b) Pal, S.; Mukherjee, M.; Sen, B.; Mandal, S. K.; Lohar, S.; Chattopadhyay, P.; Dhara, K. Chem. Commun. 2015, 51, 4410-4413. (c) Cao, Y.; Li, D. - W.; Zhao, L. - J.; Liu, X. - Y.; Cao, X. - M.; Long, Y. - T. Anal. Chem. 2015, 87, 9696-9701. (d) Xu, Z.; Yan, J.; Li, J.; Yao, P.; Tan, J.; Zhang, L. Tetrahedron Lett. 2016, 57, 2927-2930. (e) Yan, J.-W.; Zhu, J.-Y.; Tang, Q.-F.; Zhou, L.-F.; Yao, P.-F.; Lu, Y.-T.; Tan, J.-H.; Zhang, L. RSC Adv. 2016, 6, 65373-65376. (f) Li, Y.; Wang, X.; Yang, J.; Xie, X.; Li, M.; Niu, J.; Tong, L.; Tang, B. Anal. Chem. 2016, 88, 11154-11159. (g) Feng, W.; Liu, D.; Feng, S.; Feng, G. Anal. Chem. 2016, 88, 10648-10653. (h) Feng, W.; Liu, D.; Zhai, Q.; Feng, G. Sens. Actuators, B 2017, 240, 625-630. (i) Feng, W.; Hong, J.; Feng, G. Sens. Actuators, B 2017, 251, 389-395. (j) Liu, K.; Kong, X.; Ma, Y.; Lin, W. Angew. Chem. 2017, 129, 13674-13677. (k) Feng, S.; Liu, D.; Feng, W.; Feng, G. Anal. Chem. 2017, 89, 37543760.

(11) Kim, H. M.; Cho, B. R. Chem. Rev. 2015, 115, 5014-5055.

(12) Nguyen, B. T.; Anslyn, E. V. Coord. Chem. Rev. 2006, 250, 31183127.

(13) (a) Toscani, A.; Marín-Hernández, C.; Moragues, M. E.; Sancenón, F.; Dingwall, P.; Brown, N. J.; Martínez-Máñez, R; White, A. J. P.; Wilton-Ely, J. D. E. T. Chem. - Eur. J. 2015, 21, 14529-14538. (b) Moragues, M. E.; Toscani, A.; Sancenón, F.; Martínez-Máñez, R.; White, A. J. P.; Wilton-Ely, J. D. E. T. J. Am. Chem. Soc. 2014, 136, 11930-11933.

(14) Alcaraz, M. J.; Vicente, A. M.; Araico, A.; Dominguez, J. N.; Terencio, M. C.; Ferrándiz, M. L. Br. J. Pharmacol. 2004, 142, 11911199.

(15) (a) Wu, L.; Wang, R. Pharmacol. Rev. 2005, 57, 585-630. (b) Vicente, A. M.; Guillén, M. I.; Alcaraz, M. J. Exp. Biol. Med. 2003, 228, 514-516.

(16) García-Fernández, A.; García-Laínez, G.; Ferrándiz, M. L.; Aznar, E.; Sancenón, F.; Alcaraz, M. J.; Murguía, J. R.; Marcos, M. D.; Martínez-Máñez, R.; Costero, A. M.; Orzáez, M. J. Controlled Release 2017, 248, 60-70. 